\title{
The Interaction between the Large-Scale EVs and the Power Grid*
}

\author{
Yuan Huang, Junyong Liu, Xiaodong Shen, Tingting Dai
}

School of Electrical Engineering and Information, Sichuan University, Chengdu, China. Email: hymerry@sina.com

Received Septembers $10^{\text {th }}$, 2012; revised January $17^{\text {th }}$, 2013; accepted January $24^{\text {th }}$, 2013

Copyright (C) 2013 Yuan Huang et al. This is an open access article distributed under the Creative Commons Attribution License, which permits unrestricted use, distribution, and reproduction in any medium, provided the original work is properly cited.

\begin{abstract}
With the problem of global energy shortage and people's awareness of energy saving, electric vehicles receive worldwide attention from government to business. Then the load of the power grid will rapidly increase in a short term, and a series of effects will bring to the power grid operation, management, production and planning. With the large-scale penetration of electric vehicles and distributed energy gradually increased, if they can be effectively controlled and regulated, they can play the roles of load shifting, stabling intermittent renewable energy sources, providing emergency power supply and so on. Otherwise they may have a negative impact, which calls for a good interaction of electric vehicles and power grid. Analyzed the status of the current study on the interaction between the electric vehicles and the power grid, this paper builds the material basis, information architecture and the corresponding control method for the interaction from the aspect of the energy and information exchanging, and then discusses the key issues, which makes a useful exploration for the further research.
\end{abstract}

Keywords: Smart Grid; Power System; Electric Vehicles; Interaction; V2G

\section{Introduction}

With the deepening of the global energy crisis, advances in battery technology and energy saving requirements of the growing importance make electric vehicles worldwide widespread attention and promotion in recent years [1]. Electric vehicles as a terminal energy consumption of products, when their number is less, are not enough to have a significant impact on the grid, but when tens of thousands of vehicles are present these can move loads of randomness, intermittent structure and operation of the grid are bound to have a significant impact. The introduction of electric vehicles will fully reflect the smart grid to a large number of "plug and play" of distributed power generation centralized added features to improve the smart grid to become the embodiment of core values [2].

Research has been carried out electric vehicle charging impact on the grid, the demand charge, the charger, charge pile model, charging station monitoring system, charging system standards, network planning and coordination of resources and utilization [3-6]. Studies have shown that large-scale electric vehicle charging at peak load will *The Young Scientific Research Foundation of Sichuan University (No.
2011SCU11062). lead to "peak plus peak" phenomenon, increasing the difficulty of peaking power and backup power' increase [7,8]; large-scale electric vehicle charging loads will change the load distribution network structure, the existing distribution system planning criteria and rules of operation are facing new problems [9]; electric vehicle charging network operation increases the randomness of the uncertainty factor. Various studies have made on vehicle to grid (V2G). V2G is used in the distributed large-scale electric vehicle as an energy storage system. It makes charging stations for electric vehicles or energy storage unit as the interaction with the grid, considering the access and participation in other clean energy sources such as FM [10].

The development of electric vehicles is closely related to electricity, charging facilities penetration, and large scale electric vehicle charging is to bring new load growth, transmission, distribution facilities planning and other issues. The interaction of electric vehicles and grid power is through the interaction of supply and demand and adjust to achieve the rational use of resources. The study of electric cars and charging stations and grid (generation, transmission and distribution, with use) will reveal the interaction kinds of relationships. This includes the use 
of interactive communication, the interface system integration technology, for electric vehicles end-user devices and information integration to achieve the optimal grid resources rational use of the whole process.

This paper analyzes the energy and information in electric vehicles and grid interaction between the process of interaction, and it also summarizes the present situation of two-way interaction of the structural framework for the realization of the process proposed research questions and analysis of relevant technologies to achieve the reduced mass electric vehicle charging and discharging of the power grids, reducing the power grid operation and investment costs, resulting in good economic and social benefits.

\section{Interact among the Electric Vehicle, the Charging Stations and the Smart Grid}

[11] points out that the interaction is the essence of the grid alternative energy, compatible use and economic interaction. The interaction among the electric vehicles, charging stations and smart grid is based on smart grid technology, by data through the network to read the realtime, high-speed, bi-directional transmission. They make end-users of energy and information with the grid interaction. Interaction of electric vehicles and smart grid is shown in Figure 1.

Interaction with the electric car is the essence of smart grid energy to achieve the optimal use of the optimal allocation of social resources; it can be shown in Figure 2 of its three levels of interaction analysis.

\subsection{The Physical Architecture of Interact among the Electric Vehicles, Charging Stations and Smart Grid}

The application of the Internet of Things using in electric vehicles and charging stations is the electric vehicles and charging stations to interact with the physical basis of the smart grid, which is an extension and expansion of the Internet [12], it will extend and expand the client to elec-

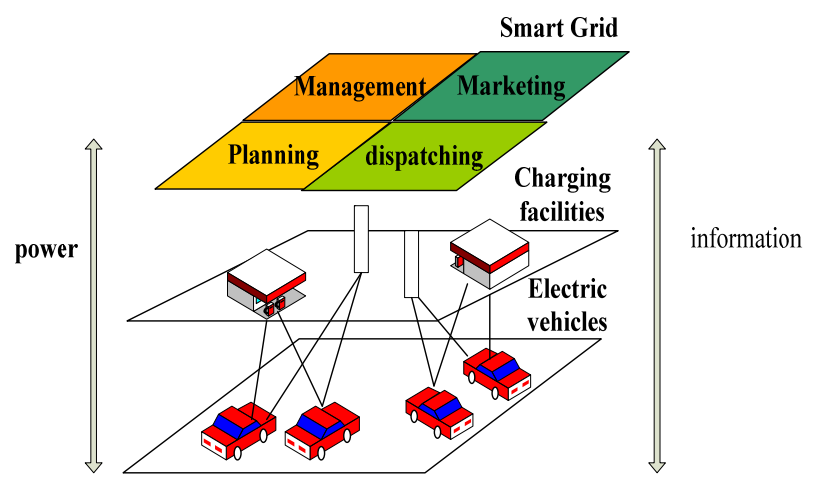

Figure 1. The sketch map of the interaction between the EVs and the smart grid. tric cars, charging facilities exchange of information between the grid and communication, and it covers things electric vehicles and battery charging facilities, things, information center of things. In the Internet of Things, Radio Frequency Identification (RFID) tags stores on electric vehicles with the interoperability specifications and information, through wireless data communication network automatically collecting them charging facilities management information systems for electric vehicle identification. Then through open computer network to a dispatching production management system, information exchange and sharing of consumer electric vehicles have achieved as a "transparent” administration.

Internet of things electric vehicles and batteries use the Global Positioning System (GPS) and Internet to do electric vehicles in real time and non real-time information collection, collation and transmission. It is shown in Figure 3. Car Smart electric vehicle information terminal is the harmonization of export, which covers the batteryrelated information, such as the current remaining battery electric vehicles and so on, through the wireless network

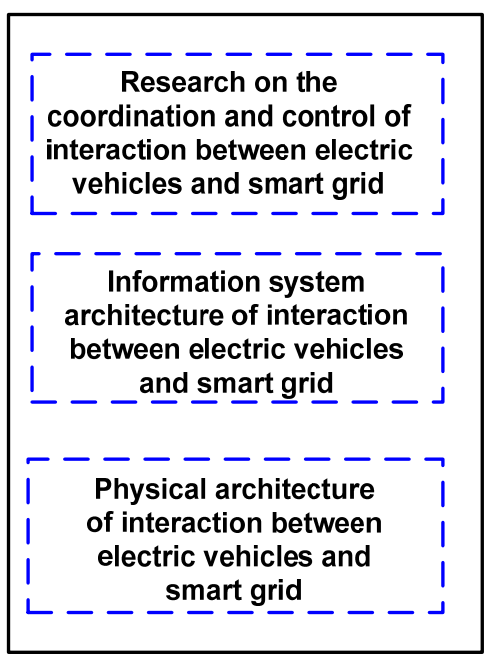

Figure 2. The hierarchical structure of the interaction between the EVs and the smart grid.

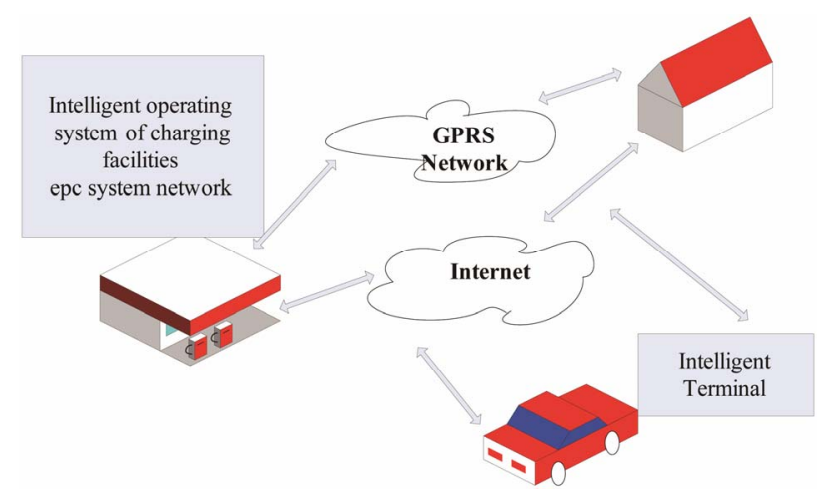

Figure 3. The internet of things framework of EVs and charging station. 
and exchange data management center running in the background, through the RFID identification of electric vehicles (battery) and the state location for settlement, management and control for advanced data services, computing support. Things Smart charging facilities operating system is on the one hand the work of running stateaware devices, such as battery charge time remaining, etc., on the other record electricity consumption information and security monitoring and other information.

\subsection{Electric Vehicles and Smart Grid Interactive Information System Architecture}

Smart Grid will connect more devices, including a variety of intelligent sensors and control components, power equipment, which need to improve the grid digitization, and deepen the generation, transmission, substation, distribution, consumption and scheduling all aspects of data collection, transmission, storage and use of [13]. It achieved through data center centralized collection of information throughout the network, and the use of highspeed communication networks operating equipment online state detection and transmission of information, which constitutes the interaction of electric vehicles and smart grid foundation. In the implementation of the charging stations on the main dispatch operations through information management system (Figure 4) and connection dispatching communication and information systems, they must follow the existing IEC 61970, IEC 61968, IEC 61850 and Common Information Model (CIM) standard series, unified naming convention, the public power grid and the data model standard unified modeling [14].

The charging station side, on the one hand response is for the electric vehicle charging management services, on the other hand need to assume management responsibility for electric vehicles. It needs to interact with power systems control centers all state variables, measurement, electric energy, etc., for the operation of the data should be scheduled through the charging station in the background and operational information management system for data collection, sorting, statistics, classification, analysis of the formation of the back data sources.

\subsection{Coordination Controls for the Interaction of Electric Vehicles and Smart Grid}

Electric vehicles and smart grid interactive coordination control are aimed at considering a large number of random, intermittent load cases, improving the power FM peaking, load capacity of peak load shifting, and promote the economical use of energy, to improve the overall system energy utilization efficiency. This will involve charging stations and grid load characteristics to optimize the coordination of a new model to run, electric vehicle battery energy density, fast and slow charging and the power of technology and tie; plug-in electric vehicles and coordinated operation of the control grid technology and technical standards implementation; charging facilities and their optimal allocation of the interaction between the grid.

\section{The Key Issues of Electric Vehicles and Smart Grid Interaction}

\subsection{Electric Vehicle Charging and Discharging Characteristics of the Loads Analysis}

Studies $[15,16]$ from the load management discuss the use of low power for electric vehicle charging time, lower peak-valley difference, change load patterns, which will directly affect the production of grid operation and management. In $[17,18]$, the studies can be seen when hun-

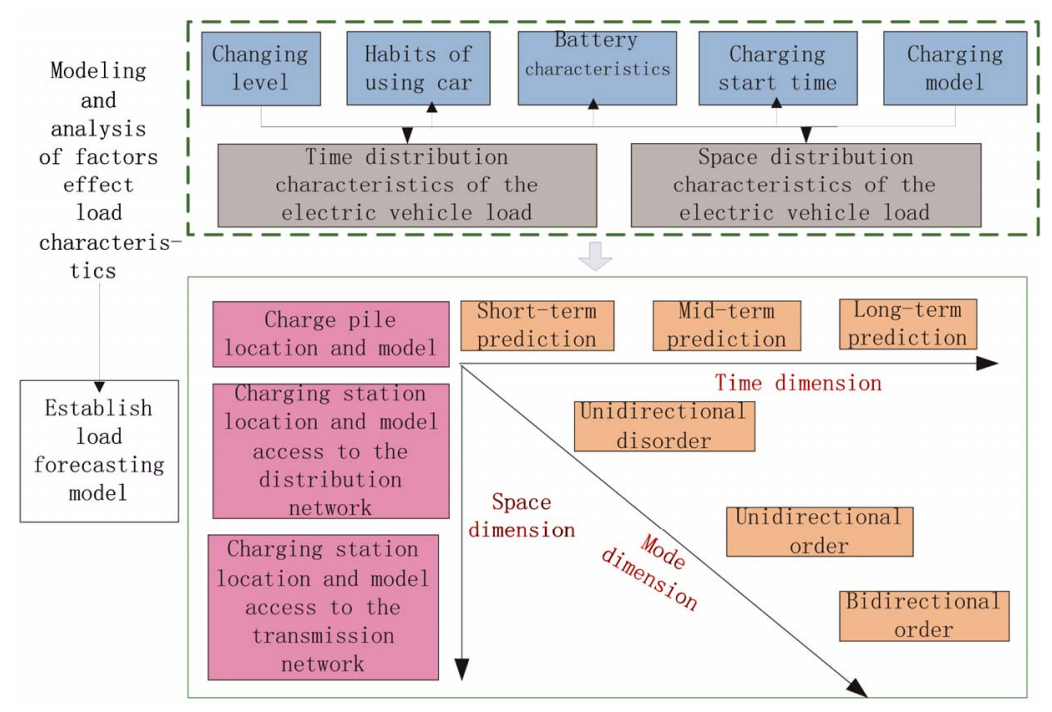

Figure 4. The load forecasting model of electric vehicles. 
dreds of millions of electric vehicle charging will increase the disorder in the peak power load, need to increase the system's peak power and peak-shaving backup. They may to existing power equipment operation bring overload, voltage the limit, power quality and other problems that may affect safe and reliable power system operation. [19] studies have shown that electric vehicle charging will bring net loss of disorder increases, impact grid dispatch and economy.

Characteristics of the electric vehicle charging and discharging are the foundation research on the load electric vehicles and grid interaction. Load of electric vehicles is the same penetration of electric vehicles, charging; charge level, battery capacity, electric vehicles the user's habits, such as charging start time closely related. This need based on deterministic and non-deterministic analysis methods combined with artificial intelligence and predictive tools in order to form accurate forecasts of electric vehicle load.

\subsection{Electric Vehicle Charging Facilities Planning}

The construction of electric vehicle charging stations is the popular premise and foundation for electric vehicles, and in expanding electricity market demand, improve the efficiency of energy supply network is widely used in electric vehicles, one of the necessary conditions. Electric vehicle charging station planning must take full account of the grid structure, transportation structure, and behavioral characteristics of electric vehicle charging, charging infrastructure investment and other aspects, so it is a multi-objective, multi-variable nonlinear optimization problem.

[6] has been proposed based on the amount of electric car ownership, user type, driving range, charging demand planning stages of charging facilities for the program; [20] considers the promotion of electric vehicles in the early stages, through the convenient charging method for electric vehicle development, and establishes of considering the cost of different locations, charge by charge investors the minimum investment and charging stations to minimize the cost of the multi-objective optimization model, the dynamic constraints of time with the heuristic algorithm; the literature [21] analysis electric vehicles charging behavior of stochastic dynamic characteristics. A line of electric vehicle charging service system mathematical model, optimal charging facilities is established using cost model to guide the user at the right time to recharge, combing with the role of TOU pricing system, effective to reduce the peak power difference and improve the power grid load factor; [22] consider the flow due to the load and charge the uneven distribution. The weighted Voronoi diagram method is proposed to determine the priority of charging stations planning to form a charging station network planning combination of traffic.

Therefore, the combination of electric vehicles and electric vehicle development trend of various spatial and temporal characteristics of the load, use of optimization algorithms to achieve the parties to maximize return on investment, to meet the demand to maximize the way to achieve charging facilities planning stages of addressing still has a relatively constant volume high research value.

\subsection{V2G}

The concept of V2G is first put forward by the Kempton and Letendre [23], and it means the electrical energy storage onboard Electric Vehicles (EV). It refers to the smart grid technology support. It will be in a suspended state for large-scale electric vehicles focused on the latter distributed as a removable storage unit, in a controlled state to achieve the energy grid, two-way information exchange. Electric vehicles can not only gain energy from the grid, but also in the running to meet the needs of users of electric vehicles under the premise of the remaining power control back to the grid, load characteristics for grid regulation, frequency response, standby power, home energy supply, can provide support services for the system to improve power grid reliability [24]. It is the interaction with the grid of electric vehicles as a typical manifestation of the way.

$[25,26]$ predict the scale of development of electric vehicles. Electric vehicles are calculated as energy storage devices to participate in the potential of V2G active output; its findings caused widespread concern at home and abroad. there are studies to V2G as a special business expanding installation [27], and made charging station as close to the $110 \mathrm{kV}$ substation standby power, access to the ring to act as focal point for short-term backup power, and especially important as the load parallel operation and emergency power and other types of more typical electric vehicle charging facilities connected to the grid of the program. [28] considers an unpredictability of wind power access to the Danish, puts forward the set electric car battery energy storage agency V2G balance system energy supply and demand. It is used to simulate the long-term power system dynamic simulation of the process, resulting in that V2G than traditional generators have fast response characteristics. [29] analyzes that in the autonomous micro-network systems, the contact of electric vehicles automatically charge and discharge and the system frequency, and large-scale simulation of the electric vehicle focus on the effect of load frequency control. [30] proposes a centralized frequency adjustment V2G electric vehicle optimization strategy. There is a consumer of electricity and electric vehicles to provide adjustment services to two aspects of the role of market prices, taking into account the factors and the battery capacity constraints in the case established the largest gains the 
model.

Existing research usually will put electric vehicles as a constant power load or use electric automobile storage characteristic its polymerization into distributed power supply. And thus it provide for the FM and standby power systems and other auxiliary services, but due to technical limitations of the grid, there no large-scale implementation of V2G, it needs from the electricity demand, supply, energy structure, price, market trading mechanism, load characteristics and other aspects of the potential impact of V2G on the grid. At present, domestic and international research in this area is still in its in- fancy.

\subsection{Advanced Interactive between Electric Vehicles and Clean Energy and Grid Smart Control}

[18] based on the traditional model of economic dispatch of electric vehicles considers the uncertainty of wind power, with the probability analysis method taking into account their expectations of electricity and contribute to build a power system model of stochastic economic dispatch. The literature [31] proposes that electric vehicle battery as distributed energy storage devices to guide makes it match with the wind power output in order to eliminate excess wind power output, and form electric vehicle charging and coordination scheduling wind power program. [7] establishes a distribution network to minimize network losses and voltage offset for the best goal of the electric vehicle charging policy model, in the model taking into account the uncertainty of load fore- casting and trend of constraints. [32] considers in the current model of electric vehicles and uncertainty of wind power. The literature [33] analyzes the distribution of electric cars and solar energy features, complementary analysis.

Electric vehicles and clean energy and smart grid control and high-level interaction in the entire power system, transmission and distribution are reflected on the use side, it should analysis the impace of the grid with electric vehicles and clean energy. It is shown in Figure 5. This process is and prices are intertwined to form complex technical and economic issues. Electric vehicle charging and discharging facilities in coordination with the power is needed for the operation of mutual inhibition between the adverse effects, to achieve the optimal use of resources and demand the greatest satisfaction. Because the different characteristics of power generation equipment with vastly different electricity load matching and multi-objective to achieve these higher-order nonlinear dynamic control problems, the traditional research questions adds a great deal of randomness, so the problem solving is more difficult and complicated.

\section{Conclusion}

The development of large-scale electricity electric vehicle development offers new opportunities for power and energy storage in the face of large-scale distributed network of electric vehicles can achieve a new "load" on the control of the new challenges. That presented in this paper for the interaction of large size of the electric cars

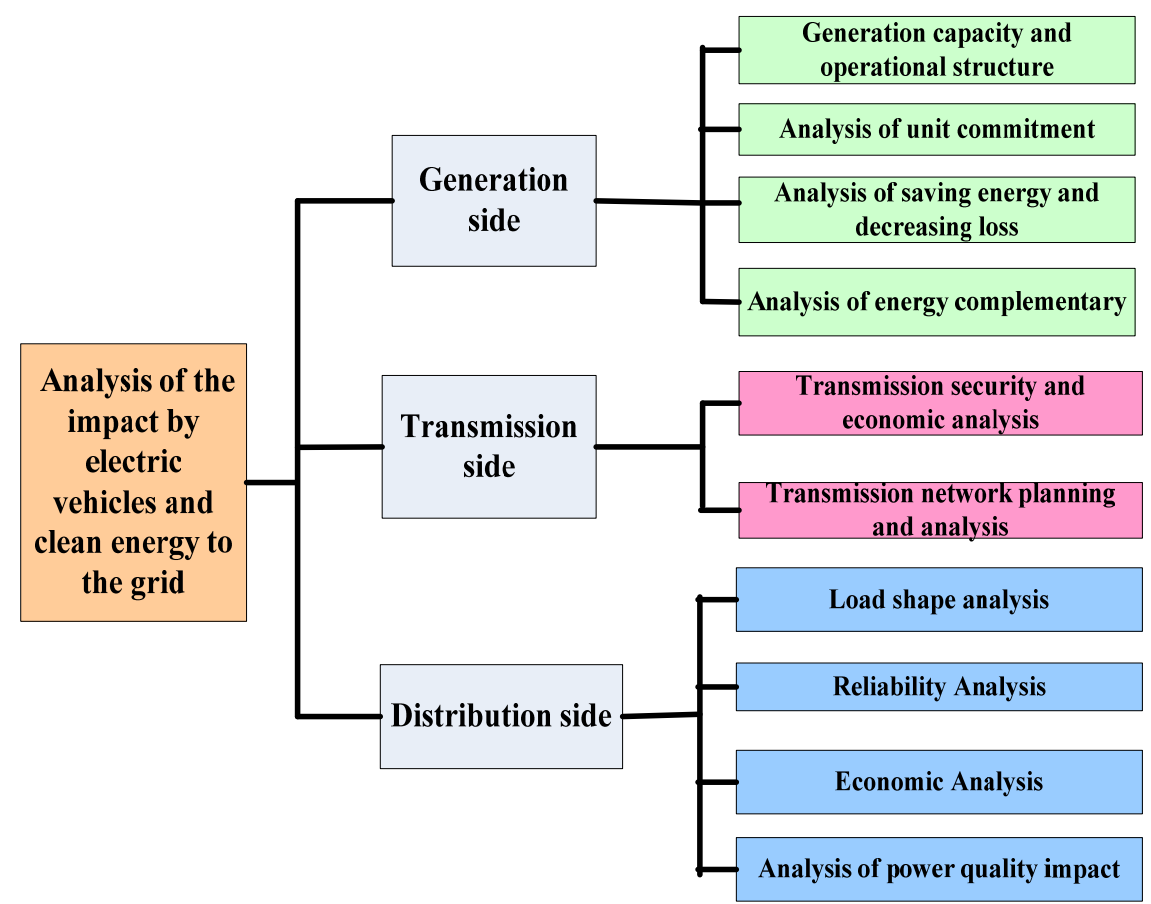

Figure 5. Evaluation of the impact of load includes plug-in electric vehicle and clear energy on power system operations. 
and grid build the energy and information exchange program, providing for further exploration of new ideas.

\section{REFERENCES}

[1] W. Zhang, B. Wu and W. F. Li, "Discussion on Development Trend of Battery Electric Vehicles in China and Its Energy Supply Mode,” Power System Technology, Vol. 33, No. 4, 2009, pp. 1-5.

[2] Y. X. Yu and W. P. Luan, "Power System and Clean Energy,” Smart Grid, Vol. 25, No. 1, 2009, pp. 7-11. (in Chinese)

[3] O. Tremblay, L. A. Dessaint and A. I. Dekkiche, “A Generic Battery Model for the Dynamic Simulation of Hybrid Electric Vehicles," Vehicle Power and Propulsion Conference, Arlington, 9-12 September 2007, pp. 284289.

[4] S. D. Jenkins, J. R. Rossmaier and M. Ferdowsi, "Utilization and Effect of Plug-In Hybrid Electric Vehicles in the United States," Vehicle Power and Propulsion Conference, Harbin, 3-5 September 2008, pp. 1-5.

[5] J. H. Zhao, F. S. Wen and Y. S. Xue, "Power System Stochastic Economic Dispatch Considering Uncertain Outputs from Plug-In Electric Vehicles and Wind Generators," Automation of Electric Power System, Vol. 34, No. 20, 2010, pp. 22-29.

[6] E.-S. Li and W. M. Wu, "Influence and Countermeasure of Electric Vehicle Battery Charging to Power Systems," East China Electric Power, Vol. 38, No. 1, 2010, pp. 0109-0113.

[7] K. Clement-Nyns, E. Haesen and J. Driesen, “The Impact of Charging Plug-In Hybrid Electric Vehicles on a Residential Distribution Grid," IEEE Transactions on Power Systems, Vol. 25, No. 1, 2010, pp. 371-380. doi:10.1109/TPWRS.2009.2036481

[8] S. Acha, T. C. Green and N. Shah, "Effects of Optimised Plug-In Hybrid Vehicle Charging Strategies on Electric Distribution Network Losses,” Transmission and Distribution Conference and Exposition, New Orleans, 19-22 April 2010, pp. 1-6.

[9] L. T. Tian, S. L. Shi and Z. Jia, “A Statistical Model for Charging Power Demand of Electric Vehicles,” Power System Technology, Vol. 4, No. 11, 2010, pp. 126-130.

[10] X. L. Yang, "The Development Trend and Foreground of the Electric Vehicle,” Auto Mobile Science \& Technology, Vol. 6, 2007, pp. 10-13.

[11] L. Q. Chen and D. S. Cui, "China New Energy Vehicle Policy,” Auto Time, Vol. 9, 2011, pp. 21-29.

[12] P. C. Sun, "The Current Situation and Development Trend of the Electric Vehicle,” Scientific Chinese, Vol. 8, 2006, pp. 44-47.

[13] L. Li and Q. B. Liu, "Study on the Influence on the EV's Usage to the Load Curve," Electrical Machinery Technology, Vol. 1, 2000, pp. 37-39.

[14] W. Kempton, J. Tomic and S. Letendre, "Vehicle-to-Grid Power: Battery, Hybrid, and Fuel Cell Vehicles as Resources for Distributed Electric Power in California,” In- stitute of Transportation Studies Report, 2001.

[15] W. Jason and P. Lincoln, "Impact of Plug-Hybrid Electric Vehicles on California's Electricity Grid,” North Carolina: Duke University, 2009.

[16] W. Kempton and J. Tomic, "Vehicle-to-Grid Power Fundamental: Calculating Capacity and Net Revenue,” Journal of Power Sources, Vol. 144, No. 1, 2005, pp. 268279. doi:10.1016/j.jpowsour.2004.12.025

[17] W. Kempton and J. Tomic, "Vehicle-to-Grid Power Implementation: From Stabilizing the Grid to Supporting Large-Scale Renewable Energy,” Journal of Power Sources, Vol. 144, No. 1, 2005, pp. 280-294. doi:10.1016/j.jpowsour.2004.12.022

[18] G. Christophe and G. George, "A Conceptual Framework for the Vehicle-to-Grid (V2G) Implementation,” Energy Policy, Vol. 37, No. 11, 2009, pp. 4379-4390. doi:10.1016/j.enpol.2009.05.053

[19] W. Kempton, V. Udo and K. Huber, "A Test of Vehicle-to-Grid (V2G) for Energy Storage and Frequency Regulation in the PJM System,” University of Delaware, Delaware, 2008.

[20] D. Larry and H. Jessica, "A New Car, A New Grid," IEEE Power \& Energy Magazine, Vol. 8, No. 2, 2010, pp. 55-61. doi:10.1109/MPE.2009.935553

[21] S. W. Hadley and A. A. Tsvetkova, “A Potential Impacts of Plug-In Hybrid Electric Vehicles on Regional Power Generation,” The Electricity Journal, Vol. 22, No. 10, 2009, pp. 56-68. doi:10.1016/j.tej.2009.10.011

[22] W. H. Stanton, "Impact of Plug-In Hybrid Vehicles on the Electric Grid,” Oak Ridge National Laboratory, Tennessee, 2006.

[23] K. Parks, P. Denholm and T. Markel, "Costs and Emissions Associated with Plug-In Hybrid Electric Vehicle Charging in the Xcel Energy Colorado Service Territory," National Renewable Energy Laboratory, Colorado, 2007. doi:10.2172/903293

[24] A. W. Rashid, D. G. Matthias and B. Michael, "Plug-in Hybrid Electric Vehicles and Smart Grid: Investigations Based on a Micro-Simulation," The 12th International Conference of the International Association for Travel Behaviour Research, Jaipur, 2009.

[25] M. Rowand, “The Electricity Utility-Business Case,” PlugIn Conference, San Jose, 2009.

[26] J. Taylor, A. Maitra and M. Alexander, "Evaluation of the Impact of Plug-In Electric Vehicle Loading on Distribution System Operations,” Power \& Energy Society General Meeting, Calgary, 26-30 July 2009, pp. 1-6.

[27] E. S. Li and W. M. Wu. "Influence and Countermeasure of Electric Vehicle Battery Charging to Power Systems," East China Electric Power, Vol. 38, No. 11, 2010, pp. 109-113.

[28] Y. J. Chen, "Study on the Influence on Power Quality By Electric Vehicle Charging Equipment," Hubei Electric Power, Vol. 33, No. 6, 2009, pp. 48-50.

[29] J. G. Kang, Z. L. Wei and D. M. Cheng, "Research on Electric Vehicle Charging Mode and Charging Stations Construction,” Power Demand Side Management, Vol. 11, 
No. 5, 2009, pp. 64-66.

[30] L. Steven, "Plug-In Hybrid Electric Vehicles and the Vermont Grid: A Scoping Analysis,” University of Vermont Transportation Center, Vermont, 2007.

[31] M. K. Meyers, K. Schneider and R. Pratt, "Impacts Assessment of Plug-In Hybrid Vehicles on Electric Utilities and Regional US Power Grids Part 1: Technical Analysis,” Pacific Northwest National Laboratory, Washington DC, 2007.

[32] P. Denholm and W. Short, “An Evaluation of Utility Sys- tem Impacts and Benefits of Optimally Dispatched PlugIn Hybrid Electric Vehicles,” National Renewable Energy Laboratory, Colorado, 2007.

[33] Y. Gurkaynak and A. Khaligh. “A Control and Power Management of a Grid Connected Residential Photovoltaic System with Plug-In Hybrid Electric Vehicle (PHEV) Load," Applied Power Electronics Conference and Exposition, Washington DC, 15-19 February 2009, pp. 20862091. 